Reprint Series

21 January 1994, Volume 263, pp. 358-361

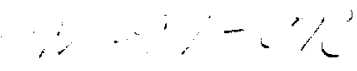

,$+ \cdots$,

\title{
Wind Streaks on Venus: Clues to Atmospheric Circulation
}

Ronald Greeley, ${ }^{\star}$ Gerald Schubert, Daniel Limonadi, Kelly C. Bender, William I. Newman, Peggy E. Thomas, Catherine M. Weitz, and Stephen D. Wall 


\title{
Wind Streaks on Venus: Clues to Atmospheric Circulation
}

\author{
Ronald Greeley," Gerald Schubert, Daniel Limonadi, \\ Kelly C. Bender, William I. Newman, Peggy E. Thomas, \\ Catherine M. Weitz, Stephen D. Wall
}

Magellan images reveal surface features on Venus attributed to wind processes. Sand dunes, wind-sculpted hills, and more than 5830 wind streaks have been identified. The streaks serve as local "wind vanes," representing wind direction at the time of streak formation and allowing the first global mapping of near-surface wind patterns on Venus. Wind streaks are oriented both toward the equator and toward the west. When streaks associated with local transient events, such as impact cratering, are deleted, the westward component is mostly lost but the equatorward component remains. This pattern is consistent with a Hadley circulation of the lower atmosphere.

Earth-based observations, data from flybys, and measurements from landed spacecraft reveal that Venus has a rocky surface with an average temperature of $753 \mathrm{~K}$ beneath an acid-laden, predominantly $\mathrm{CO}_{2}$ atmosphere with a surface pressure of 90 bars. Ideas about atmospheric circulation on Venus are based on cloud motions ( $a t \approx 60 \mathrm{~km}$ altitude) deduced from ultraviolet images taken by flyby and orbiting spacecraft (1$5)$, wind speeds inferred from Doppler tracking of Venera $(6,7)$ and Pioneer Venus (8) atmospheric probes, radio tracking of balloons (at about $50 \mathrm{~km}$ altitude) during the VEGA mission $(9,10)$, and motions of features (at about $50 \mathrm{~km}$ altitude) in infrared images of the planet (1113). Zonal winds are westward with speeds of $\approx 100 \mathrm{~m} \mathrm{~s}^{-1}$ at cloud heights $(\approx 60 \mathrm{~km}$ altitude), decreasing approximately monotonically with proximity to the surface to speeds of $\approx 10 \mathrm{~m} \mathrm{~s}^{-1}$ at a height of $10 \mathrm{~km}$ (14). No eastward winds have ever been seen in the atmosphere. Meridional winds are both northward and southward but with speeds generally not exceeding several

R. Greely, K. C. Bender, P. E. Thomas, Department of Geology. Box 871404, Arizona State University Tempe, AZ 85287-1404.

G. Schubert, D. Limonadi, W. I. Newman, Department of Earth and Space Sciences, University of California Los Angeles, Los Angeles, CA 90024-1567.

C. M. Weitz and S. D. Wall, Jet Propulsion Laboratory, 4800 Oak Grove Drive, Pasadena, CA 91109

"To whom correspondence should be addressed meters per second even at cloud heights (14). Wind speeds at the surface are from 0.3 to $1.0 \mathrm{~m} \mathrm{~s}^{-1}(15)$, well within the range necessary to move loose surface sand and dust (16).

Accordingly, the principal mode of atmospheric circulation on Venus from just above the lowest scale height (at $\approx 10 \mathrm{~km}$ altitude) to $\approx 100 \mathrm{~km}$ is a zonal retrograde (westward) superrotation of the atmosphere (14). However, global circulation models of the lower atmosphere (especially below $\approx 10$ $\mathrm{km}$ altitude) have hitherto been mostly unconstrained because of the paucity of relevant observations. Theoretical models of the lower atmosphere circulation involve a Hadley circulation driven by solar energy deposition in the deep atmosphere, preferentially at low latitudes $(17-21)$. This circulation involves equatorward surface winds, upflow over the equator, poleward winds aloft, and downflow at high latitudes. A similar circulation is expected in both the northern and southern hemispheres of Venus.

We report here the first observations that constrain the global circulation pattem of the lower atmosphere of Venus. These are the wind streaks seen in Magellan radar data $(22,23)$ that result from the interaction of the atmosphere and the surface. These wind streaks not only reveal the nature of the lower atmospheric circulation but also reflect the influence of the strong westward winds of the cloud-level atmosphere. 
Venusian wind streaks are radar backscatter patterns that contrast with the surrounding surface features $(23,24)$. Both radar-bright (high radar backscatter, generally caused by rough surfaces) and radardark (low radar backscatter) wind streaks occur (Fig. 1). Although streaks range from less than $5 \mathrm{~km}$ to several hundred kilometers in length, typical streaks are about 20 $\mathrm{km}$ long. Streaks occur in several shapes, including plume, fan, and long-narrow forms. The most abundant, informally termed "zebra" streaks, consist of multiple, alternating radar-dark and -bright streaks. Nearly all zebra streaks are associated with deposits inferred to be ejecta from young impact craters.

Similar to wind streaks on Earth and Mars (25-27), venusian streaks are thought to be visible on radar images because of differences in the distribution of windblown particles in relation to surface wind patterns. Wind tunnel experiments simulating conditions on Venus (16) suggest that particles moved by the wind are smaller than $\approx 1 \mathrm{~cm}$ and that most would be a few hundred micrometers in diameter. Depending on the wind shear stress, surfaces may be completely stripped of loose grains (leaving exposed bedrock), covered with large $(>1 \mathrm{~cm})$ particles too massive to be removed by the wind (forming a lag deposit), or blanketed with grains transported from elsewhere and deposited

A

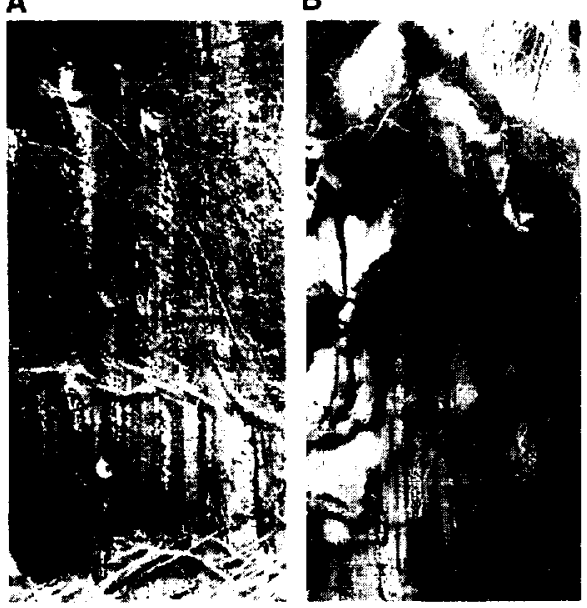

Fig. 1. (A) Radar-bright streak (top of image, associated with cone-shaped hill) and "zebra" streaks at $9^{\circ} \mathrm{N}, 67^{\circ} \mathrm{E}$, north of Hestia Rupes. The wind is inferred to have blown from north to south at the time of streak formation. The largest bright streak is about $35 \mathrm{~km}$ long (Magellan F-MIDR 10N065). (B) Radar-dark streaks at $46^{\circ} \mathrm{N}, 127.1^{\circ} \mathrm{E}$, in Northern Niobe Planitia. Part of Anake Terresa is visible in the upper portion of the image. The wind is inferred to have blown from north (top) to south (bottom) at the time of streak formation. The longest streak is about 40 $\mathrm{km}$ long (Magellan F-MIDA 45N126). in areas of low surface winds. Extremely rough surfaces, such as some lava flows, may serve as traps for wind-transported particles. Each of these surfaces would have different radar backscatter properties (24), depending on several considerations including the areal extent and thickness of surficial deposits, exposed bedrock and its surface toughness, and possible eolian bedforms such as dunes.

Many wind streaks on Earth are related to wind flow patterns over and around topographic features such as small hills. Flow separation and reattachment, as well as the generation of local vortices, lead to distinctive zones of surface erosion and deposition that are functions of the geometry of the topographic feature and the wind
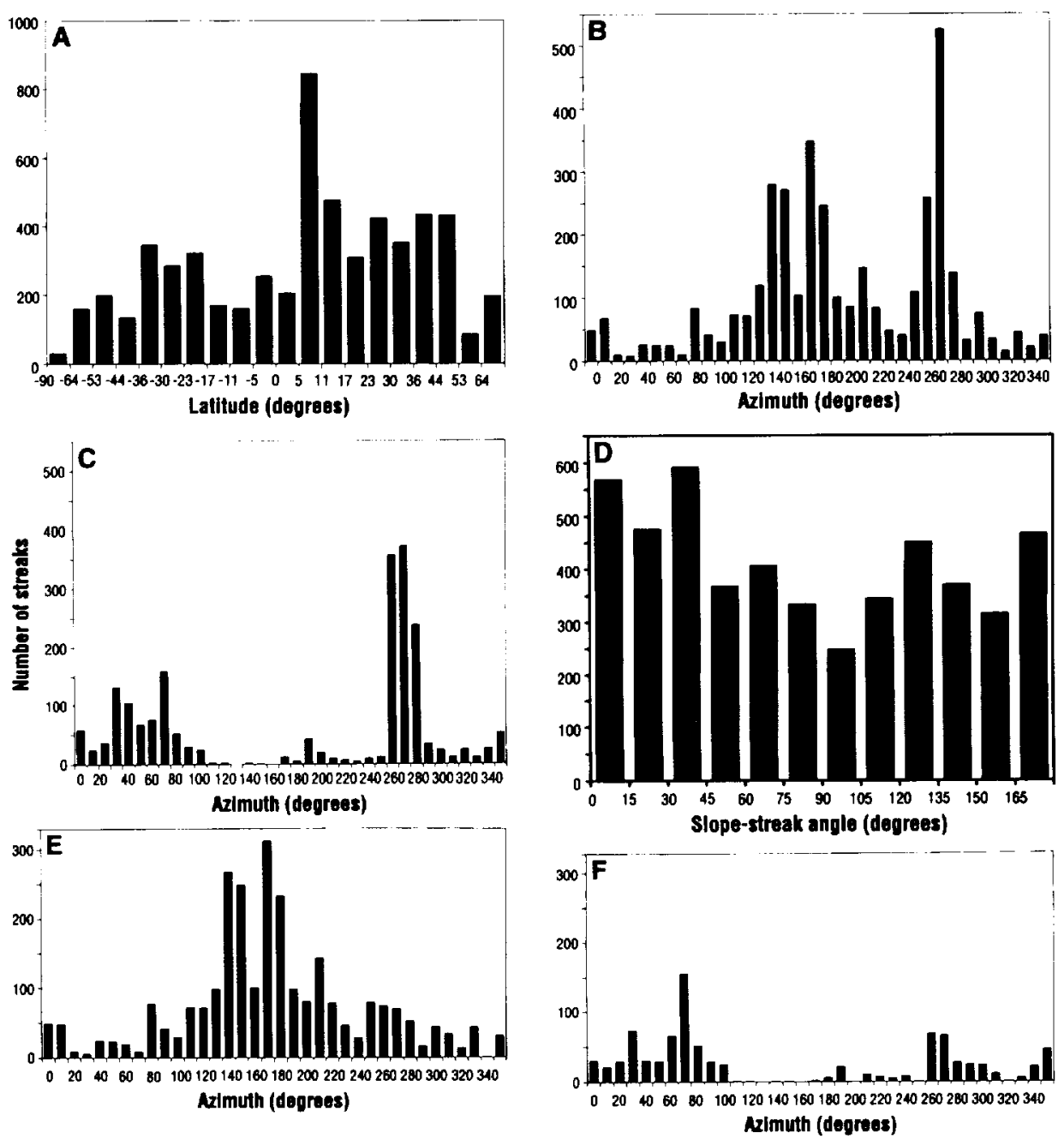

Fig. 2. (A) Histogram of venusian wind streaks in bands of equal area latitude. (B) Azimuths of all wind streaks in the global data base for the northern hemisphere, with north at $0^{\circ}$. (C) Azimuths of all wind streaks in the global database for the southern hemisphere, with north at $0^{\circ}$. (D) Distribution of wind streak orientations with respect to local slope, showing that streaks occur randomly with regard to slope. The downslope is at $0^{\circ}$ and the upslope is at $180^{\circ}$. Angle is the difference in degrees between downslope azimuth and streak azimuth. (E) Azimuths of subset of database (3666 streaks) in which Type $P$ wind streaks that may have formed in response to transient events have been deleted (northern hemisphere). North is at $0^{\circ}$. (F) Azimuths of subset of data with deletion of Type $P$ wind streaks that may have formed in response to transient events (southern hemisphere). North is at $0^{\circ}$.

SCIENCE • VOL. $263 \cdot 21$ JANUARY 1994 
rains (23). Both of these geologic settings could supply material appropriate for erosion and deposition by wind. However, not all impact craters and tectonically disrupted areas have associated eolian features, suggesting that (i) winds sufficiently strong to transport particles may not occur everywhere on the planet; (ii) some surfaces may be too rough, preventing particle movement by wind; (iii) particles may not form, are cemented or bonded by some process, or are too cohesive for movement by the wind; or (iv) particles may be depleted at some sites of old impact craters because of their removal and redistribution by surface winds.

Little is known about the time of formation of wind streaks and their lifetime. As part of this study, analysis of sequential air photos of wind streaks in the Mojave Desert and Bolivia showed little change over a 14-year period. On the other hand, martian wind streaks were observed to appear, disappear, or change in shape in as little as 38 days (25). A preliminary search of Magellan repetitive images has not revealed any changes in venusian wind streaks in the $\approx 1$ year between observations, although further analysis is in progress.

Regardless of the exact mode of formation of the contrasts in radar backscatter, wind streaks on Earth, Mars, and Venus probably represent local wind directions at the time of streak formation and provide the opportunity to assess regional and global atmospheric circulation patterns (25, 30). To assess potential patterns on Venus, all wind streaks identified on Magellan images were mapped, measured, and classified with the use of the scheme of Greeley et $a$. (23). Histograms of streak orientations were plotted for the northern and southern hemispheres (Fig. 2, B and C). Orientations are given as azimuths in the downwind direction. In the northern hemisphere there is a bimodal distribution of azimuths; one mode is toward the south-southeast and the other is toward the west. The azimuths in the southern hemisphere are also bimodal, with one mode toward the northnortheast and the second mode toward the west. Thus, the global wind directions inferred from the streaks are generally equatorward and roward the west.

Before the Magellan mission, some predictions (29) suggested local atmospheric circulation involving slope winds. If these conditions existed, then wind streaks might be more indicative of topography than of general circulation. Histograms of the orientation of wind streaks with regard to local slope (Fig. 2D) show random orientations, suggesting that slope is not a major factor in the determination of streak azimuths.

Streaks may form in response to wind circulation patterns over many years or long- er, or in response to transient events such as impact cratering. An assessment of disturbances to the atmosphere by cratering processes on Venus suggests that turbulent winds could be generated near the impact (31). Wind streaks formed in association with these transient events may not represent general atmospheric circulation. We term these "Type P" streaks because they occur within the ejecta deposits of impact craters defined by Campbell et al. (32) as having "parabolic halo" ejecta blankets. We separated Type P streaks in the database in the following manner: $A$ rectangular area covering the ejecta deposits was defined for each of the 50 craters identified by Campbell et al. The areas were outlined by the visual inspection of potential ejecta deposits and vary in size. Typical areas exceed 500 by 700 $\mathrm{km}$, oriented parallel to the parabola axis. Streaks in each area that have azimuths oriented $\pm 20^{\circ}$ radial to the crater were "tagged" as Type P streaks.

Most Type P streaks are $>100 \mathrm{~km}$ long and have predominantly westward azimuths, parallel to the parabola axes. Type $P$ streaks typically are radar-dark or zebra forms, both considered to result from the deposition of sand and dust. We suggest that these streaks develop by the dynamic interaction of crater ejecta particles, the atmospheric response to the impact, and the westward zonal winds. Strcaks may form by the deposition of impact ejecta raised to great heights and transported downwind (westward) by the high altitude, westward superrotation of the atmosphere. The depositional pattern is influenced by near-surface roll convection cells generated by either the impact heating of the surface and atmosphere or the impactinduced upwelling of magma from beneath the surface and is oriented parallel to the westward atmospheric circulation. This model is supported by observations that there is a decrease in zebra streak length down-range from some craters (such as Stowe crater) and that zebra streaks do not occur in association with craters $<30 \mathrm{~km}$ in diameter, suggesting insufficient impact-generated heat or associated magma upflow to induce near-surface atmospheric convection. In this model, Type P streaks are not indicative of present general near-surface atmospheric circulation but reflect the westward superrotation of the upper atmosphere at the time of impact. Therefore, the westward superrotation of the atmosphere extends at least several hundred million years into the past, the inferred time of impact.

The database contains 3666 streaks with the removal of Type $P$ streaks. Histograms of streak azimuths in the northern and southern hemispheres (Fig. 2, E and F) show that the strong westward component seen with the inclusion of Type $P$ streaks is mostly absent in both hemispheres, al- though the equatorward component remains. The predominant trend in the southern hemisphere is for streaks to be aligned northeastward (average at the $\approx 50^{\circ}$ azimuth), with a smaller fraction of streaks aligned westward. In the northern hemisphere, the streaks are mainly aligned south or equatorward (average at the $170^{\circ}$ azimuth), with a smaller fraction of streaks aligned westward. The predominantly equatorward orientation of the non-P Type streaks in both hemispheres is consistent with a classic lower atmosphere Hadley circulation. The presence of equatorwardoriented streaks in the highest latitude bands of both hemispheres indicates the possibility of Hadley cell circulation reaching to the poles. The Hadley circulation represents an average of the lower atmospheric wind patterns over the time period (unknown) recorded by the wind streaks.

The differences in wind-streak azimuth distributions between the northern and southern hemispheres suggest differences in the lower atmospheric circulation regimes of the two hemispheres, hemispheric differences in the supply or transportability of small particles, or as yet unrecognized geologic or topographic hemispheric influences on wind streaks. There are no a priori theoretical reasons to expect hemispheric differences in global atmospheric circulation patterns on Venus. The northeastward trend in the southern hemisphere and the slightly east of south trend in the northern hemisphere are due to the Coriolis force, although the Rossby number ( $\mathrm{Ro}_{0}$ ) for Venus' atmosphere is estimated to be large compared with unity (14). The value of Ro is the ratio of the inertial force to the Coriolis force, and if Ro $>>1$ then Coriolis effects should be relatively unimportant. The large estimate of Ro is based on the planetary rotation rate; Ro might be smaller and the Coriolis force might be more important if the atmospheric superrotation rate is a more appropriate measure of dynamical influences.

Type $P$ streaks are associated with impact craters and are considered to result from the interaction of crater ejecta, convection cells in the atmosphere generated by impact, and westward zonal winds in the upper atmosphere at the time of impact. The remaining 3666 streaks (excluding Type P streaks) have orientations indicative of near-surface Hadley cell circulation averaged over the time recorded by the streaks. These Hadley cells could extend to polar latitudes.

\section{REFERENCES AND NOTES}

\footnotetext{
1. M. J. Belton, S. Smith, G. Schubert, A. D. Del Genio, J Atmos Sci 33, 1394 (1976) 2. S. S. Limaye Icarus 73. 212 (1988)

3. ___. C Grassotti, M. J. Kuetemeyer, ibid., $p$ 193
} 
4. A. D. Del Genio and W. B. Rossow, J. Atmos. Sci. 47, 293 (1990)

5. W. B. Rossow. A. D. Del Genio, T. P. Eichler, ibid. p. 2053.

6. M. Marov et al., ibid 30, 1210 (1973).

7. V. V. Kerzhanovich and M. Ya. Marov, in Venus, D. M. Hunten, L. Colin, T. M. Donahue, V. I. Moroz, Eds. (Univ. of Arizona Press, Tucson, 1983), pp 776-778.

8. C. C. Counselman III, S. A. Gourevitch. R. W King. G. B. Loriot, A. G. Prinn, Science 205, 85 (1979).

9. J. E. Blamont et al, ibid 231,1422 (1986)

10. R. A. Preston et al, ibid., p. 1414.

11. M. J. S. Belton et al., ibid. 253, 1531 (1991)

12. D. Crisp et al., ibid., p. 1538

13. A. W. Carlson et al, ibid., p. 1541

14. G. Schubert, in (7), pp. 681-765.

15. V. S Avduevsky et al. Cosmic Res. 14, 622 (1976).

16. R. Greeley et al., Icarus 57, 112 (1984).

17. E. Kálnay de Rivas, J. Atmos. Sci. 30, 763 (1973).

18. P. H. Stone, ibid. 31, 1681 (1974)

19. G. Schubert et al, J. Geophys. Res 85, 8007 (1980)

20. W. B. Rossow, J. Atmos. Sci. 40, 273 (1983)
21. Adv. Geophys 28A, 347 (1985)

22. R. S. Saunders et al., Science 252, 249 (1991).

23. R. Greeley et al, J. Geophys. Res. 97, 13319 (1992)

24 R. E. Arvidson et al, ibid. p. 13303

25. C. A. Sagan et al., lcarus 17, 346 (1972).

26. P. Thomas, J. Veverka, S. Lee, A Bloom, ibid 45. 124 (1981)

27. R. Greeley, P. Christensen, R. Carrasco, Geology 17. 665 (1989)

28. R. Greeley, J. D. Iversen, J. B. Pollack, N. Udovich, B. White, Science 183, 847 (1974).

29. R. S. Saunders, A. R. Dobrovolskis, R. Greeley, S. D. Wail, Geophys Res. Lett. 17, 1365 (1990)

30. P. Thomas and J Veverka, J. Geophys. Res. 84 , 8131 (1979)

31 P H Schultz ibid. 97, 16183 (1992)

32. D. B. Campbell et al., ibid. p. 16249

33. We thank R. D. Baker and D. L. Bindschadler for helpful discussions and $E$. Lo for developing programs to manipulate the database. Supported by the National Aeronautics and Space Administration through the Magellan Project and the of fice of Planetary Geoscience.

17 August 1993; accepted 18 November 1993 
